\section{Red to Far-red Ratio During Seed Development Affects Lettuce Seed Germinability and Longevity}

\author{
Samuel Contreras ${ }^{2}$ \\ Departamento de Ciencias Vegetales, Pontificia Universidad Católica de \\ Chile, Av Vic Mackenna 4860, Casilla 306-22, Santiago, Chile
}

Mark A. Bennett and James D. Metzger

Department of Horticulture and Crop Science, Ohio State University, Columbus, OH 43210-1086

\author{
David Tay ${ }^{1}$ \\ Ornamental Plant Germplasm Center, Ohio State University, Columbus, $\mathrm{OH}$ \\ 43210-1086
}

\section{Haim Nerson \\ Agricultural Research Organization, Department of Vegetable Crops, Newe Ya'ar Research Center, P.O. Box 1021 Ramat Yishay, 30095, Israel}

Additional index words. abscisic acid, light, Lactuca sativa, maternal environment, photosensitivity, seed development, thermoinhibition

\begin{abstract}
Thermoinhibition and photosensitivity are two characteristics of lettuce seed that frequently affect its stand. The main objective of this study was to evaluate the hypothesis that lettuce seed germinability and longevity are affected by the red to far-red light ratio (R:FR) under which seeds maturate. 'Tango' lettuce seeds were produced in growth chambers under one of two treatments: 1) red-rich light ( $R$ treatment) and 2) farred-rich light (FR treatment). For both treatments, the percentage of normal seedlings germinated at $20{ }^{\circ} \mathrm{C}$-light was $\approx 100 \%$. When germinated under the light, seeds from the $R$ treatment exhibited a higher germination percentage and a faster germination (under a broader range of temperatures) than seeds from the FR treatment. When germinated in the dark, seeds from the $R$ treatment germinated $100 \%$ between 12 and $23{ }^{\circ} \mathrm{C}$ and over $50 \%$ at $30{ }^{\circ} \mathrm{C}$, whereas seeds from the FR treatment germinated less than $35 \%$ between 12 and $23{ }^{\circ} \mathrm{C}$ and less than $5 \%$ at $30{ }^{\circ} \mathrm{C}$. Seeds from the $\mathrm{R}$ treatment had lower abscisic acid (ABA) content and were better able to germinate when exposed to external ABA concentrations than seeds from the FR treatment. Seed longevity as assessed by the accelerated aging test was higher in seeds from the FR treatment, indicating that red-rich light was detrimental to longevity. In another experiment, lettuce seeds that developed under similar conditions were harvested at approximately the moment of maximum dry weight accumulation and desiccated in dark, far-red, red, or fluorescent + incandescent light. Seeds desiccated under red light exhibited higher dark germination than the other treatments; however, no differences were observed in thermoinhibition or longevity. These results suggest that lettuce seed produced in an environment with a high R:FR light ratio will exhibit reduced thermoinhibition and photosensitivity as compared with production in a lower R:FR light environment.
\end{abstract}

Lettuce (Lactuca sativa L.) is one of the most commonly cultivated fresh vegetable crops in the world and its establishment

Received for publication 25 July 2008. Accepted for publication 23 Oct. 2008.

Salaries and research support were provided by state and federal funds appropriated to The Ohio State University, Ohio Agricultural Research and Development Center as well as a Fulbright Scholarship to S. Contreras.

We thank Hank Hill from Seed Dynamics Inc. for providing lettuce seeds and technical advice used in this study and Miller McDonald and Elaine Grassbaugh for critical review of this manuscript. ${ }^{1}$ Current address: International Potato Center, Apartado 1558, Lima 12, Peru.

${ }^{2}$ To whom reprint requests should be addressed; e-mail scontree@uc.cl. was produced (Contreras et al., 2008b; Wurr et al., 1986). In a previous study (Contreras et al., 2008b), we observed that the maternal light environment during 'Tango' lettuce seed development significantly affected seed weight, germinability, and longevity. Seeds produced under a light environment consisting of $8 \mathrm{~h}$ fluorescent light were lighter and exhibited lower photosensitivity, thermoinhibition, and longevity than seeds produced under $8 \mathrm{~h}$ fluorescent light $+8 \mathrm{~h}$ incandescent light. The red to far-red (R:FR) ratio of fluorescent and incandescent light was $\approx 6.8$ and 1.0 , respectively, and the critical period during seed development for the light environment effects on seed germinability and longevity was at the end of seed development after physiological maturity (moment of maximum seed dry weight accumulation). Because of the importance of phytochrome in regulating photosensitivity (Shinomura, 1997) and the methodology used in these experiments (extension of photoperiod with a far-red-rich source of light), we hypothesized that light quality, rather than photoperiod, would be the critical factor explaining differences in germinability and longevity between lettuce seeds produced under different light environments. Light quality during seed development affected the photosensitivity in Arabidopsis thaliana (Hayes and Klein, 1974; McCullough and Shropshire, 1970) and Piper auritum (Orozco-Segovia et al., 1993). Cresswell and Grime (1981) studied seed photosensitivity of 21 species and concluded that light conditions during seed drying strongly affect light requirements for germination.

Understanding the influence of the maternal environment light quality on seed germinability and longevity could assist in the production and handling of high-quality lettuce seeds. The main objective of this study was to test the hypothesis that lettuce seeds produced under a light environment with higher R:FR ratio have better germinability and lower longevity than seeds produced under a light environment with lower R:FR ratio.

\section{Materials and Methods}

Two experiments were conducted to determine the effects of the light spectral composition on lettuce seed quality: 1) effects during lettuce seed production (intact plants) and 2) effects during artificial seed desiccation (flower heads removed from the mother plant). and uniformity of seedling emergence, making it difficult to attain successful crop establishment in the field (Ryder, 1999; Wien, 1997). Levels of thermoinhibition and photosensitivity vary not only among lettuce genotypes (Gray, 1975; Kozarewa et al., 2006; Sung et al., 1998), but also among seed lots of the same cultivar (Contreras et al., 2008a, 2008b; Sung et al., 1998; Wurr et al., 1986). Differences in germinability among seedlots within cultivars are mainly the result of the particular environmental conditions under which each seedlot
Expt. 1: Effects of light quality during seed production

'Tango' lettuce plants were grown in the greenhouse in 1.75-L plastic pots filled with a soilless growing media (Metromix 360; Scotts, Marysville, OH). Plants were irrigated daily and each pot was fertilized weekly with $50 \mathrm{~mL}$ of a solution containing $35 \mathrm{mg}$ nitrogen, $15 \mathrm{mg}$ phosphorus, and 29 mg potassium (Peters Professional; Scotts). 
After bolting and before flowering, 3 months after planting, the plants were transferred into growth chambers representing one of two treatments: 1) red-rich light ( $\mathrm{R}$ treatment) consisting of a main light period of $10 \mathrm{~h}$ fluorescent light with a photosynthetic photon flux $(P P F)$ of $224 \pm 27 \mu \mathrm{mol} \cdot \mathrm{m}^{-2} \cdot \mathrm{s}^{-1}$ and a $\mathrm{R}: \mathrm{FR}=6.8$ plus a supplement of $4 \mathrm{~h}$ fluorescent light with a $P P F=29 \pm 2$ and R:FR $=$ 8.4; and 2) far-red-rich light (FR treatment) consisting of a main light period of $10 \mathrm{~h}$ fluorescent and incandescent light with a $P P F=227 \pm 31 \mu \mathrm{mol} \cdot \mathrm{m}^{-2} \cdot \mathrm{s}^{-1}$ and a $\mathrm{R}: \mathrm{FR}=$ 1.5 plus a supplement of $4 \mathrm{~h}$ incandescent light with a $P P F=23 \pm 2$ and $\mathrm{R}: \mathrm{FR}=1.0$. In both treatments, there were $10 \mathrm{~h}$ of dark and the 4-h supplemental light period, which was split using $2 \mathrm{~h}$ before and $2 \mathrm{~h}$ after the main light period. The temperature was $25{ }^{\circ} \mathrm{C}$ during the main and complementary light periods and $15{ }^{\circ} \mathrm{C}$ during dark. The R:FR ratio was calculated as the sum of wavelengths between 656 and $664 \mathrm{~nm}$ divided by the sum of wavelengths between 726 and 734 nm. Light spectral irradiance was measured by using a portable spectroradiometer (LI1800; LI-COR Biosciences, Lincoln, NE). There were 12 plants randomly assigned to each treatment (chamber). Two months later, seeds were harvested manually by extracting only fully matured flower heads (dry and open with visible seeds of $\approx 8.5 \%$ water content on a fresh weight basis) of each plant. Seeds were cleaned and then stored in paper envelopes inside a storage room at $4{ }^{\circ} \mathrm{C}$ with $25 \%$ relative humidity (RH) until evaluation. The equilibrium seed water content during storage was $5.1 \pm 0.2 \%$ (fresh weight basis).

Seed evaluation. For fresh and dry weight determinations, three samples of 50 seeds per treatment were weighed before and after drying in an oven at $103{ }^{\circ} \mathrm{C}$ for $48 \mathrm{~h}$.

The standard germination test was conducted using four replicates of 50 seeds each. In transparent square plastic boxes $(11 \times 11 \times$ $4 \mathrm{~cm}$ ), the seeds were placed on two layers of blotter paper (Anchor Paper Co., St. Paul, $\mathrm{MN}$ ) moistened with distilled water. These boxes were placed in a germination chamber at $20{ }^{\circ} \mathrm{C}$ under constant fluorescent light $\left(P P F \approx 30 \mu \mathrm{mol} \cdot \mathrm{m}^{-2} \cdot \mathrm{s}^{-1}\right)$. After 4 and $7 \mathrm{~d}$, normal seedlings were counted as germinated [International Seed Testing Association (ISTA), 1999].

Other germination tests were conducted using four replicates of 50 seeds each. The seeds were placed in a petri dish $(9 \mathrm{~cm}$ diameter) on two layers of blotter paper moistened with $10 \mathrm{~mL}$ distilled water or 10 $\mathrm{mL}$ solution of various concentrations of $( \pm)$ abscisic acid (ABA; Sigma-Aldrich, St. Louis, MO). Germination tests at different ABA concentrations were performed at $20^{\circ} \mathrm{C}$ under constant light with daily counting of germinated seeds (radicle emergence, $2 \mathrm{~mm}$ or greater) to $7 \mathrm{~d}$. Germination at 30 ${ }^{\circ} \mathrm{C}$ under constant light was recorded daily for $7 \mathrm{~d}$. The germination index (GI) was calculated according to the following equation (Maguire, 1962):

$\mathrm{GI}=($ ratio of germinated seeds day 1$) / 1+\ldots+($ ratio of germinated seeds day

" $\mathrm{X}$ ")/ " $\mathrm{X}$ " $+\ldots+$ (ratio of germinated seeds last count)/days to final count.

Germination in dark was conducted using black petri dishes on a thermogradient table (Series \#16065; Seed Processing Holland B.V., Enkhuizen, The Netherlands) at 12.4, $17.3,23.4$, or $29.7{ }^{\circ} \mathrm{C}$; germination was evaluated after $4 \mathrm{~d}$.

The effect of FR light on germination was investigated by germinating seeds at $20^{\circ} \mathrm{C}$ in dark under constant white light $(\mathrm{R}: \mathrm{FR}=11.1$, photon flux $\left.=24 \mu \mathrm{mol} \cdot \mathrm{m}^{-2} \cdot \mathrm{s}^{-1}\right)$ or under constant FR light (R:FR $=0.01$, photon flux $\left.=10 \mu \mathrm{mol} \cdot \mathrm{m}^{-2} \cdot \mathrm{s}^{-1}\right)$. Germination was evaluated after $4 \mathrm{~d}$.

For the accelerated aging (AA) test, lettuce seeds were aged at $41{ }^{\circ} \mathrm{C}$ with $\approx 100 \%$ $\mathrm{RH}$ for $72 \mathrm{~h}$ and then germinated following the standard germination protocol. Normal seedlings (ISTA, 1999) were evaluated after $11 \mathrm{~d}$.

Abscisic acid extraction and determination. ABA extraction and determination from mature seeds were performed as described by Roth-Bejerano et al. (1999) with some modifications. Sixty seeds were frozen in liquid nitrogen and stored at $-80^{\circ} \mathrm{C}$. After lyophilization, the seeds were ground to powder in liquid nitrogen and then weighed. Methanol containing $0.5 \mathrm{~g} \cdot \mathrm{L}^{-1}$ citric acid monohydrate and $100 \mathrm{mg} \cdot \mathrm{L}^{-1}$ butylated hydroxytoluene was added at a ratio of $1.0 \mathrm{~mL}$ for each $10 \mathrm{mg}$ of dry tissue. The suspension was stirred at $4{ }^{\circ} \mathrm{C}$ in dark for at least $20 \mathrm{~h}$ and then centrifuged at $1500 \mathrm{~g}$ for 10 min. ABA was determined from this supernatant by using anti-ABA monoclonalspecific antibodies and competitive enzymelinked immunosorbent assay test according to instructions from the Phytodetek ${ }^{\circledR}$ ABA Test Kit (Agdia, Elkhart, IN).

The data are presented as average values \pm SE of the average.

\section{Expt. 2: Effects of light quality during artificial seed desiccation}

Nine lettuce plants (cv. Tango) were cultivated in the greenhouse as described for Expt. 1. Approximately 14 flower heads per plant were labeled the day of flowering and harvested manually $14 \mathrm{~d}$ later. Immediately after harvest, 30 flower heads were randomly assigned to each of the following desiccation treatments: 1) dark, 2) total light, 3 ) red light, and 4) far-red light. Seed water content at harvest was calculated on seeds from five flower heads. Seeds from the flower heads assigned to the dark, red light, and farred light treatments were extracted in a dark room illuminated with green light (tested to not induce germination), whereas seeds from flower heads assigned to the total light treatment were extracted under fluorescent light in the laboratory. After extraction, the seeds were placed inside square plastic boxes $(11 \times 11 \times 4 \mathrm{~cm})$ containing $100 \mathrm{~mL}$ saturated sodium bromide solution. Seeds were placed on a mesh layer suspended in the plastic boxes to prevent direct contact between the seeds and $\mathrm{NaBr}$ solution. All boxes containing the seeds were placed in a chamber at $25{ }^{\circ} \mathrm{C}$ with constant fluorescent and incandescent light. Boxes of the dark treatment were wrapped with aluminum foil to prevent light from reaching the seeds. The sides and bottom of all other boxes were also wrapped with aluminum foil and only the top cover was transparent. Seeds from the total light treatment received a mix of fluorescent and incandescent light with a R:FR $=1.11$. By using filters located over the box covers, seeds from the red and far-red light treatment were under light with R:FR of 45.53 and 0.01 , respectively. The RH inside the boxes was $\approx 57 \%$. After $3 \mathrm{~d}$, a sample of 48 seeds (12 seeds from each treatment) was used for seed water content determination and the rest of the seeds, separated by treatment, were placed inside paper envelopes at $4{ }^{\circ} \mathrm{C}$ with $25 \%$ RH until evaluation. This experiment was repeated four times and for the statistical analysis, the average values were used.

Seed evaluation and data analysis. Dark germination at $20{ }^{\circ} \mathrm{C}$, germination at $30{ }^{\circ} \mathrm{C}$ in light, and AA tests were conducted using 50 seeds from each replication and similar methodology as described for Expt. 1. Differences among treatments were analyzed using analysis of variance and the least significant difference $(\alpha=0.05)$ procedures in SAS (SAS Institute, Cary, NC). Percentages and GI values were transformed to the arcsine of the square root of the fraction value before statistical analysis.

\section{Results}

Expt. 1. Lettuce seeds produced under the FR treatment were $\approx 5 \%$ heavier than seeds from the $\mathrm{R}$ treatment; however, standard germination was similar for seeds produced under both light treatments (Table 1). After $72 \mathrm{~h} \mathrm{AA}$ (at $41{ }^{\circ} \mathrm{C}$ and $100 \% \mathrm{RH}$ ), standard germination of seeds from the $\mathrm{R}$ treatment was more affected, producing less than $11 \%$ normal seedlings compared with $98 \%$ normal seedlings from the FR treatment (Table 1). Abscisic acid content in mature seeds from the FR treatment was $65 \%$ higher than in seeds from the R treatment (Table 1).

Seeds produced under the $\mathrm{R}$ treatment did not require light to germinate between 12.4 and $23.4{ }^{\circ} \mathrm{C}$ and had greater than $50 \%$ germination in dark at $29.7^{\circ} \mathrm{C}$, whereas seeds from the FR treatment germinated no more than $35 \%$ in dark between 12.4 and $23.4{ }^{\circ} \mathrm{C}$ and less than $5 \%$ in dark at $29.7^{\circ} \mathrm{C}$ (Table 1; Fig. 1). At $20{ }^{\circ} \mathrm{C}$ under constant FR light, seeds from the $\mathrm{R}$ treatment germinated only $6 \%$, whereas no germination $(0 \%)$ was recorded for seeds from the FR treatment (Table 1). 
Table 1. Quality attributes for 'Tango' lettuce seed produced under two different light environments. ${ }^{2}$

\begin{tabular}{|c|c|c|}
\hline Parameter & $\mathrm{R}$ treatment $\mathrm{t}^{\mathrm{y}}$ & FR treatment ${ }^{\mathrm{x}}$ \\
\hline Dry weight $\left(\mathrm{mg} \cdot \mathrm{seed}^{-1}\right)$ & $0.753 \pm 0.002$ & $\overline{0.792 \pm 0.029}$ \\
\hline Standard germination $(\%)$, normal seedlings & $98.0 \pm 1.4$ & $99.0 \pm 0.6$ \\
\hline Germination $(\%), 20^{\circ} \mathrm{C}-$ white $^{\mathrm{w}}$ light & $99.0 \pm 0.6$ & $100.0 \pm 0.0$ \\
\hline Germination $(\%), 20{ }^{\circ} \mathrm{C}$-dark & $99.5 \pm 0.5$ & $28.5 \pm 4.0$ \\
\hline Germination $(\%), 20^{\circ} \mathrm{C}$-far-red ${ }^{v}$ light & $6.0 \pm 2.9$ & $0.0 \pm 0.0$ \\
\hline Normal seedlings (\%) after $\mathrm{AA}^{\mathrm{u}}$ & $10.5 \pm 1.0$ & $98.0 \pm 1.3$ \\
\hline Seed ABA content (pg.mg dry weight ${ }^{-1}$ ) & $26.5 \pm 2.1$ & $43.8 \pm 2.9$ \\
\hline
\end{tabular}

${ }^{2}$ Data are the means of four replicates of 50 seeds each \pm SE.

${ }^{\mathrm{y}} \mathrm{R}$ treatment: $10 \mathrm{~h}$ of light with red to far-red ratio (R:FR) $=6.8$ and $4 \mathrm{~h}$ of light with $\mathrm{R}: \mathrm{FR}=8.4$.

${ }^{x} \mathrm{FR}$ treatment: $10 \mathrm{~h}$ of light with R:FR $=1.5$ and $4 \mathrm{~h}$ of light with $\mathrm{R}: \mathrm{FR}=1.0$.

${ }^{\mathrm{w}} \mathrm{R}: \mathrm{FR}=11.1$, photon flux $=24 \mu \mathrm{mol} \cdot \mathrm{m}^{-2} \cdot \mathrm{s}^{-1}$.

${ }^{\mathrm{V}} \mathrm{R}: \mathrm{FR}=0.01$, photon flux $=10 \mu \mathrm{mol} \cdot \mathrm{m}^{-2} \cdot \mathrm{s}^{-1}$.

uA $=$ accelerated aging of the seeds at $41^{\circ} \mathrm{C}$ with $\approx 100 \%$ relative humidity for $72 \mathrm{~h}$.

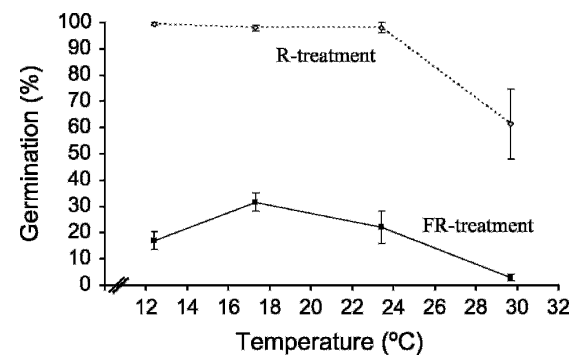

Fig. 1. Germination percentages at different temperatures in dark of 'Tango' lettuce seeds produced under red-rich light $(\mathrm{R}$ treatment; broken line) or far-red-rich light (FR treatment; solid line). Data are means of four replicates of 50 seeds each \pm SE.

When germinating under light at temperatures between 13.0 and $33.0^{\circ} \mathrm{C}$, germination was close to $100 \%$ for seeds from both treatments, but between 34.5 and $38.0{ }^{\circ} \mathrm{C}$ germination of seeds from the FR treatment was decreased more than for seeds from the $\mathrm{R}$ treatment, which were able to germinate over $94 \%$ and $81 \%$ at 36.5 and $38.0{ }^{\circ} \mathrm{C}$, respectively (Fig. 2A). Seeds from the R treatment

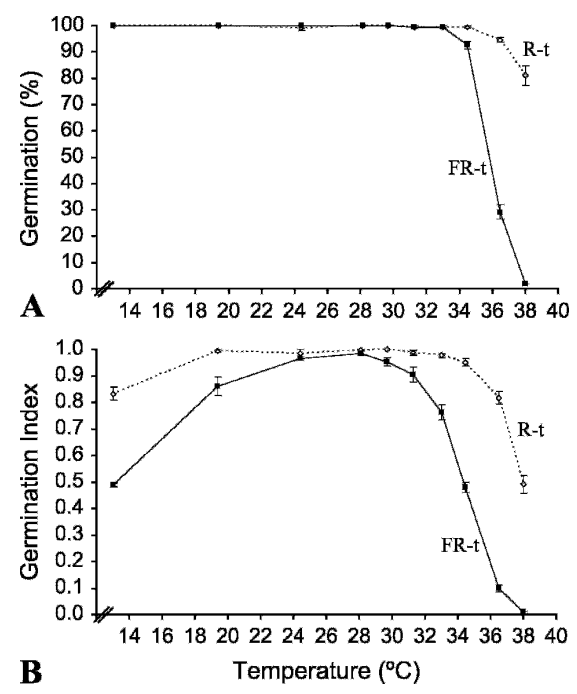

Fig. 2. Germination percentage (A) and germination index (B) at different temperatures in light of 'Tango' lettuce seeds produced under redrich light (R-t; broken line) or far-red-rich light (FR-t; solid line). Data are means of four replicates of 50 seeds each \pm SE. had a GI close to 1.0 (complete germination during the first $24 \mathrm{~h}$ ) between 19.4 and $34.5^{\circ} \mathrm{C}$ and over 0.8 at 13.0 and $36.5^{\circ} \mathrm{C}$ (Fig. 2B). On the other hand, seeds from the FR treatment exhibited a GI close to 1.0 at 24.4 and $28.1^{\circ} \mathrm{C}$ but were more affected by extreme temperatures than seeds from the $\mathrm{R}$ treatment, having a GI lower than 0.5 at $13.0{ }^{\circ} \mathrm{C}$ or temperatures over $34.5^{\circ} \mathrm{C}$ (Fig. 2B).

Spectral composition during lettuce seed production also affected seed sensitivity to exogenous ABA (Fig. 3). In both treatments, germination percentage and GI were reduced by higher ABA concentrations (Fig. 3), but seeds from the FR treatment were more sensitive than seeds from the $\mathrm{R}$ treatment.

Expt. 2. Average seed water content (fresh weight basis) at harvest (14 d after flowering) and after desiccation was $37.8 \pm 0.5 \%$ and $6.7 \pm 0.4 \%$, respectively. The light condition during desiccation affected seed germination in the dark; seeds desiccated under red light exhibited $67 \%$ germination, significantly more than seeds from the other three treatments (Table 2). Production of normal seedlings after AA was no more than $27 \%$ for any of the desiccation treatments and seeds from the dark treatment exhibited significantly lower performance than seeds from the total light and far-red light treatments (Table 2). Germination at $30{ }^{\circ} \mathrm{C}$ was poor $(12 \%$ or less) for seeds from any of the desiccation treatments with no significant differences among treatments (Table 2).

\section{Discussion}

Previously, we reported that lettuce seeds produced under a long day (LD) treatment were heavier, had lower germinability, better longevity, and higher $\mathrm{ABA}$ content than seeds produced under a short day (SD) treatment (Contreras et al., 2008b). In those experiments, the light extension of the LD treatment was attained by using incandescent light, which is rich in FR wavelengths, and we hypothesized that the observed differences were primarily caused by differences in the R:FR ratio between the SD (rich in $\mathrm{R}$ light) and LD (rich in FR light) treatments. Based on this hypothesis, the $\mathrm{R}$ and FR treatments are equivalent to the SD and LD treatments, respectively. Thus, if our hypothesis is correct, seeds from the FR treatment should be heavier, have lower germinability, better longevity, and higher ABA content than seeds from the $\mathrm{R}$ treatment.

Seeds from the FR treatment were 5\% heavier than seeds from the $\mathrm{R}$ treatment (Table 1), which is consistent with our hypothesis. Previously (Contreras et al., $2008 \mathrm{~b}$ ), it was suggested that the differences in seed weight could be associated with the presence of fewer seeds in plants growing under FR-rich light, so the seeds would be heavier as a result of lower competition for photosynthates. The number of seeds per plant is a function of the number of flower heads per plant and the number of seeds per flower head. In this experiment, no differences in the number of seeds per flower head were observed (data not shown). If light treatments were intended to be used during lettuce seed production, it would be important to test their effects on seed yield, specifically the number of seeds per plant.

Seeds from both treatments exhibited standard germination close to $100 \%$ (Table 1). However, when germination was evaluated at suboptimal conditions, seeds produced under $\mathrm{R}$ treatment exhibited better germinability than seeds from the FR treatment (Figs. 1, 2, and 3). Photosensitivity and thermoinhibition are two lettuce seed characteristics that frequently impede rapid and uniform emergence of seedlings in the field (Ryder, 1999; Wien, 1997), which is essential for attaining high yield and quality in a single harvest (Wien, 1997; Wurr and Fellows, 1985). Seeds produced under R treatment did not have photosensitivity and reached full germination in dark between 12 and 23 ${ }^{\circ} \mathrm{C}$, whereas seeds from the FR treatment did not germinate more than $35 \%$ under similar conditions (Fig. 1). Tango is a lettuce cultivar characterized as being very photosensitive (Contreras et al., 2008a, 2008b; H.J. Hill, personal communication) and these results confirm that the dependence of light for seed germination may be modified by the light conditions of the maternal environment (Contreras et al., 2008b; Hayes and Klein, 1974; McCullough and Shropshire, 1970). At $30{ }^{\circ} \mathrm{C}$, dark germination of seeds from both treatments was affected; however, seeds from the $\mathrm{R}$ treatment germinated over $50 \% \mathrm{com}$ pared with only $3 \%$ for seeds from the FR

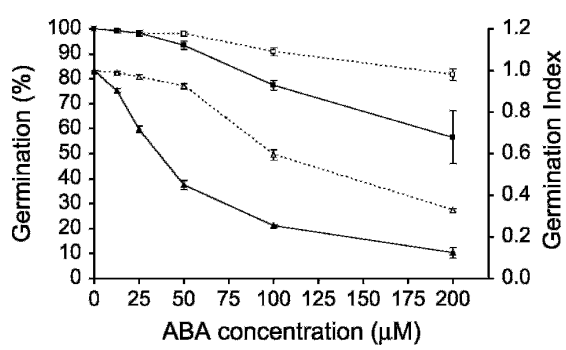

Fig. 3. Germination percentage (squares) and germination index (triangles) at different external abscisic acid (ABA) concentrations of 'Tango' lettuce seeds produced under red-rich light (broken line) or far-red-rich light (solid line). Data are means of four replicates of 50 seeds each $\pm \mathrm{SE}$. 
Table 2. Effect of spectral composition during artificial desiccation on quality attributes for 'Tango' lettuce seeds with $38 \%$ water content harvested $14 \mathrm{~d}$ after flowering and desiccated at $20{ }^{\circ} \mathrm{C}, 57 \%$ relative humidity, and under different light treatments. ${ }^{\mathrm{z}}$

\begin{tabular}{lcccc}
\hline Treatment & $\begin{array}{c}\text { Dark germination } \\
\text { at } 20{ }^{\circ} \mathrm{C}(\%)\end{array}$ & $\begin{array}{c}\text { Normal seedlings } \\
\text { after } \mathrm{AA}^{\mathrm{x}}(\%)\end{array}$ & $\begin{array}{c}\text { Germination } \\
\text { at } 30^{\circ} \mathrm{C}(\%)\end{array}$ & $\begin{array}{c}\text { Germination index } \\
\text { at } 30^{\circ} \mathrm{C}\end{array}$ \\
\hline Total light & $14.0 \mathrm{~b}$ & $26.8 \mathrm{a}$ & 11.5 & 0.02 \\
Dark & $8.0 \mathrm{bc}$ & $6.0 \mathrm{~b}$ & 7.0 & 0.02 \\
Red & $66.5 \mathrm{a}$ & $19.5 \mathrm{ab}$ & 8.5 & 0.02 \\
Far red & $1.5 \mathrm{c}$ & $21.6 \mathrm{a}$ & 5.0 & 0.01 \\
$P$ value $^{\mathrm{w}}$ & $<0.001$ & 0.038 & 0.511 & 0.374 \\
\hline
\end{tabular}

${ }^{\mathrm{z}}$ Values in a same column with different letter(s) are significantly different according to least significant difference test $(\alpha<0.05)$.

${ }^{\mathrm{y}}$ Total light, red:far-red ratio $(\mathrm{R}: \mathrm{FR})=1.1$; red, R:FR $=45.5$; far red, R:FR $<0.01$.

${ }^{\mathrm{x}} \mathrm{AA}=$ accelerated aging of the seeds at $41{ }^{\circ} \mathrm{C}$ with $\approx 100 \%$ relative humidity for $72 \mathrm{~h}$.

${ }^{\mathrm{w}}$ Calculated from analysis of variance.

treatment (Fig. 1). These results confirm the increase of photosensitivity at higher temperatures reported by others (Fielding et al., 1992; Ikuma and Thimann, 1964; van der Woude and Toole, 1980).

When germinating under light, seeds from the $\mathrm{R}$ treatment achieved full and rapid germination over a wider range of temperatures than seeds from the FR treatment (Fig. 2). These results support the hypothesis that maternal environments with higher R:FR during seed development and maturation significantly reduce the thermoinhibition of 'Tango' lettuce seeds. This genotype is characterized by the high thermoinhibition of its seeds, which frequently require seedlots to be primed to ensure successful establishment of the crop (H.J. Hill, personal communication). Several reports have documented the effect of producing lettuce seeds at higher temperatures (e.g., 30/20 ${ }^{\circ} \mathrm{C}$ compared with $20 / 10$ ${ }^{\circ} \mathrm{C}$, day/night) in reducing seed thermoinhibition (Drew and Brocklehurst, 1990; Gray et al., 1988; Koller, 1962; Kozarewa et al., 2006; Sung et al., 1998); however, the effects of maternal light quality environment on lettuce seed thermoinhibition has rarely been studied. Seed production under modified light conditions represents a novel approach to the production of lettuce seeds with improved germinability.

Relief of photosensitivity in lettuce seeds is mediated by phytochrome, a soluble protein synthesized as $P r$, the biologically inactive form that converts into Pfr by absorbing $\mathrm{R}$ light (Shinomura, 1997). Pfr is the biologically active form of phytochrome, which may reconvert into $P r$ by absorbing FR light and is required for the occurrence of phytochrome-controlled events such as lettuce seed germination. The effects of maternal light environment on lettuce seed germinability and longevity occurred after physiological maturity, during seed maturation and drying, when seed water content varied from $\approx 43 \%$ to $\approx 8 \%$ (Contreras et al., 2008b), which is sufficient for phytochrome photoconversion in lettuce seeds (Vertucci et al., 1987). Pfr or some stable intermediate able to yield $P f r$ in the dark may persist in the seed after desiccation and harvest, and the amount of this pre-existent $P f r$ will depend on the R:FR ratio to which seeds were exposed at the end of seed development and dehydration (Taylorson, 1982). Accordingly, at harvest, seeds from the $\mathrm{R}$ treatment would have a higher amount of pre-existing Pfr than seeds from the FR treatment, which would explain the observed differences in photosensitivity (Fig. 1). This explanation is supported by the report of Cresswell and Grime (1981), who studied light requirements for germination of 21 species and observed that seeds that matured and dried within green tissues required light for germination. These authors concluded that green tissue acts as a light filter, which reduces the R:FR ratio of the light that reaches the seeds, so seeds surrounded by green tissue would have most of their phytochrome in the inactive form $(\mathrm{Pr})$.

We investigated germination under dark, white light, and FR light to test the hypothesis that differences in photosensitivity between seeds from $\mathrm{R}$ and FR treatments are explained by higher amounts of pre-existing $P f r$ in seeds from the $\mathrm{R}$ treatment. When germinated under constant FR light, seed germination decreased to $6 \%$ and $0 \%$ in seeds from the R and FR treatments, respectively (Table 1). Because FR light causes the conversion from $P f r$ to $P r$ (Taylorson, 1982), these results supports this hypothesis.

It is well documented that seed germination is regulated by the balance of two phytohormones with antagonistic effects: 1) ABA, which inhibits germination; and 2) gibberellins (GA), which induce germination (Finch-Savage and Leubner-Metzger, 2006; Kucera et al., 2005). Seeds from the $\mathrm{R}$ treatment had lower ABA content (Table 1) and germinated better under elevated external ABA concentrations than seeds from the FR treatment (Fig. 3). These results support the idea that the higher germinability observed in seeds from the R treatment would be explained, in part, by lower ABA sensitivity and content (Contreras et al., 2008b).

In species like lettuce (Toyomasu et al., 1998) and Arabidopsis (Yamaguchi et al., 1998), light induces germination through promotion of GA synthesis by Pfr. Additionally, Roth-Bejerano et al. (1999) observed that in photosensitive lettuce seeds, $2 \mathrm{~h}$ of red light during imbibition reduced the $\mathrm{ABA}$ accumulated in seeds compared with seeds imbibed in complete darkness. More recently, Seo et al. (2006) reported that in Arabidopsis seeds, the metabolism (biosynthesis and inactivation) of both GA and ABA was regulated by light (through phyto- chrome) and suggested that ABA suppresses GA biosynthesis during seed development and germination. Based on this information and the results from our previous (Contreras et al., 2008b) and current study, we speculate that maternal environments with a high R:FR light improve germinability of lettuce seeds not only by favoring $P f r$ accumulation in the mature seed, but also by inducing phytochrome-mediated responses in the seed such as the promotion of GA accumulation and inhibition of ABA biosynthesis during seed maturation and drying. A significant $\mathrm{Pfr}$ mediated control of ABA and GA metabolism during seed maturation and drying warrants further research.

Because the effects of maternal light environment on lettuce seed performance occurred between physiological maturity and harvest (Contreras et al., 2008b), the main objective of Expt. 2 was to test if $\mathrm{R}: \mathrm{FR}$ ratio during artificial seed desiccation of lettuce seeds would have similar effects on seed germinability and longevity. In this experiment, seeds were removed from the flower heads at $14 \mathrm{~d}$ after flowering (after physiological maturity), when they had $\approx 38 \%$ seed water content and while the flower heads were still green and fully covering the seeds. Desiccation occurred at a constant $25{ }^{\circ} \mathrm{C}$ and $57 \% \mathrm{RH}$ under different light conditions. As expected, the light treatment during desiccation had significant effects on the seed photosensitivity (Table 2 ). The highest dark germination percentage was for seeds desiccated under red light, whereas the lowest was for seeds desiccated under far-red light (Table 2). However, dark germination for seeds desiccated under red light was lower than seeds from the $\mathrm{R}$ treatment (Expt. 1) germinated in dark at the same temperature $(66.5 \%$ versus $99.5 \%$ germination; Tables 2 and 1, respectively). The light treatment during desiccation did not affect seed germination at $30{ }^{\circ} \mathrm{C}$ (Table 2), and seeds from the four treatments had higher levels of thermoinhibition than seeds from Expt. 1 (Fig. 2; Table 2). These results differed from what was expected based on the data from Expt. 1 and our previous research (Contreras et al., 2008b). A possible explanation for these differences is that the desiccation rates between seeds that dry in the flower heads (attached to the mother plant) and naked seeds are not the same, which would affect the time available for metabolic changes associated with $P f r$ differences. Previously, we observed that decreases in lettuce seed water content from physiological maturity $(\approx 40 \%)$ to harvest $(\approx 8 \%)$ occurred over a period of $\approx 6 \mathrm{~d}$ (Contreras et al., 2008b). Under the desiccation conditions of Expt. 2, seed water content decreased from $38 \%$ to $7 \%$ in less than $24 \mathrm{~h}$ (data not shown). Additionally, when desiccated in the flower heads, the seeds remain exposed to the light of the maternal environment for a variable time (from a few days to 3 or 4 weeks) before harvesting. During this period, seeds contain $\approx 8 \%$ water content, which is the limit for phytochrome photoconversion in lettuce 
seeds (Vertucci et al., 1987); thus, additional accumulation of Pfr may still occur in the seeds, which was not the case for seeds desiccated artificially in Expt. 2.

Longevity, or the ability of the seeds to survive long periods of storage, is another important aspect of seed quality. Previously, we reported that 'Tango' lettuce seed longevity was significantly and inversely correlated with dark germination, and it was significantly affected by the maternal light environment (Contreras et al., 2008b). Additionally, lettuce seed longevity (germination after 4 months of storage at $30^{\circ} \mathrm{C}$ and $74 \%$ $\mathrm{RH})$ was significantly correlated with results from the AA test (Contreras et al., 2008b). Thus, the AA test was used to evaluate lettuce seed longevity. As expected, lettuce seeds produced under $\mathrm{R}$ treatment had lower longevity than seeds from the FR treatment and there was an inverse relationship between seed longevity and dark germination (Table 1). In Expt. 2, although there were significant differences in results from the AA test, the values were below $27 \%$ normal seedlings for all treatments and the type of differences were not expected (i.e., lower longevity for seed desiccated under red light compared with seeds from far-red light; Table 2). In this case, these results could be explained by the methodology used in Expt. 2, as was already discussed. These results suggest a possible causal relationship between $P f r$ action and/or presence in seeds and seed longevity. Because the importance of proving this relationship for management of seed stocks by seed companies and germplasm conservation, and for understanding seed bank dynamics in native and weed plant populations, it should be further studied in lettuce and other species, especially those from the Asteraceae family.

In conclusion, our results provide evidence for the hypothesis that light quality of the maternal environment affects seed germinability and longevity of 'Tango' lettuce seeds. Higher R:FR ratios promoted the production of lettuce seeds with poorer longevity and lower levels of thermoinhibition and photosensitivity. Modification of the light environment during production of horticultural species has been suggested as a feasible practice for improvement of yield and quality of different types of crops (Clifford et al., 2004; Paul et al., 2005; Paul and Moore, 2006). Producing lettuce seeds under environments with higher R:FR ratio represents a novel approach to the production of lettuce seeds that are able to germinate rapidly and uniformly in a broader range of field conditions. However, undesired reductions in seed size and longevity are two negative effects that should also be recognized and studied. Further research should examine the feasibility of modifying light quality conditions as a measure to improve seed quality during the production of other lettuce cultivars and species.

\section{Literature Cited}

Clifford, S.C., E.S. Runkle, F.A. Langton, A. Mead, S.A. Foster, S. Pearson, and R.D. Heins. 2004. Height control of poinsettia using photoselective filters. HortScience 39:383-387.

Contreras, S., M.A. Bennett, and D. Tay. 2008a. Restricted water availability during lettuce seed production decreases seed yield per plant but increases seed size and water productivity. HortScience 43:837-844.

Contreras, S., M.A. Bennett, D. Tay, and J.D. Metzger. 2008b. Maternal light environment during seed development affects lettuce seed weight, germinability, and storability. HortScience 43:845-852.

Cresswell, E.G. and J.P. Grime. 1981. Induction of a light requirement during seed development and its ecological consequences. Nature 291:583-585.

Drew, R.L.K. and P.A. Brocklehurst. 1990. Effects of temperature of mother-plant environment on yield and germination of seeds of lettuce (Lactuca sativa). Ann. Bot. (Lond.) 66:63-71.

Fielding, A., D.K. Kristie, and P. Dearman. 1992. The temperature dependence of Pfr action governs the upper temperature limit for germination in lettuce. Photochem. Photobiol. 56:623-627.

Finch-Savage, W.E. and G. Leubner-Metzger. 2006. Seed dormancy and the control of germination. New Phytol. 171:501-523.

Gray, D. 1975. Effects of temperature on germination and emergence of lettuce (Lactuca sativa L.) varieties. J. Hort. Sci. 50:349-361.

Gray, D., D.C.E. Wurr, J.A. Ward, and J.R. Fellows. 1988. Influence of post-flowering temperature on seed development, and subsequent performance of crisp lettuce. Ann. Appl. Biol. 113:391-402.

Hayes, R.G. and W.H. Klein. 1974. Spectral quality influence of light during development of Arabidopsis thaliana plants in regulating seed germination. Plant Cell Physiol. 15:643653.

Ikuma, H. and K.V. Thimann. 1964. Analysis of germination processes of lettuce seed by means of temperature and anaerobiosis. Plant Physiol. 39:756-767.

International Seed Testing Association. 1999. International rules for seed testing. Seed Sci. Technol. 27, Supplement.

Koller, D. 1962. Preconditioning of germination in lettuce at time of fruit ripening. Amer. J. Bot. 49:841-844.

Kozarewa, I., D.J. Cantliffe, R.T. Nagata, and P.J. Stoffella. 2006. High maturation temperature of lettuce seeds during development increased ethylene production and germination at elevated temperatures. J. Amer. Soc. Hort. Sci. 131:564-570.

Kucera, B., M.A. Cohn, and G. Leubner-Metzger. 2005. Plant hormone interactions during seed dormancy release and germination. Seed Sci. Res. 15:281-307.

Maguire, J.D. 1962. Speed of germination-Aid in selection and evaluation for seedling emergence and vigor. Crop Sci. 2:176-177.

McCullough, J.M. and W. Shropshire, Jr. 1970. Physiological predetermination of germination responses in Arabidopsis thaliana (L.). Heynh. Plant Cell Physiol. 11:139-148.

Orozco-Segovia, A., M.E. Sanchez-Coronado, and C. Vazquez-Yanes. 1993. Effect of maternal light environment on seed germination in Piper auritum. Funct. Ecol. 7:395-402.

Paul, N.D., R.J. Jacobson, A. Taylor, J.J. Wargent, and J.P. Moore. 2005. The use of wavelengthselective plastic cladding materials in horticulture: Understanding of crop and fungal responses through the assessment of biological spectral weighting functions. Photochem. Photobiol. 81:1052-1060.

Paul, N.D. and J.P. Moore. 2006. Manipulation of light spectrum for crop growth. Acta Hort. 711:357-362.

Roth-Bejerano, N., N.J.A. Sedee, R.M. VanDerMeulen, and M. Wang. 1999. The role of abscisic acid in germination of light-insensitive lettuce seeds. Seed Sci. Res. 9:129-134.

Ryder, E.J. 1999. Lettuce, endive, and chicory. CABI Publishing, Wallingford, UK.

Seo, M., A. Hanada, A. Kuwahara, A. Endo, M. Okamoto, Y. Yamauchi, H. North, A. MarionPoll, T. Sun, T. Koshiba, Y. Kamiya, S. Yamaguchi, and E. Nambara. 2006. Regulation of hormone metabolism in Arabidopsis seeds: Phytochrome regulation of abscisic acid metabolism and abscisic acid regulation of gibberellin metabolism. Plant J. 48:354-366.

Shinomura, T. 1997. Phytochrome regulation of seed germination. J. Plant Res. 110:151-161.

Sung, Y., D.J. Cantliffe, and R.T. Nagata. 1998. Seed development temperature regulation of thermotolerance in lettuce. J. Amer. Soc. Hort. Sci. 123:700-705.

Taylorson, R.B. 1982. Interaction of phytochrome and other factors in seed germination, p. 323346. In: Khan, A.A. (ed.). The physiology and biochemistry of seed development, dormancy and germination. Elsevier Biomedical Press, New York, NY.

Toyomasu, T., H. Kawaide, W. Mitsuhashi, Y. Inoue, and Y. Kamiya. 1998. Phytochrome regulates gibberellin biosynthesis during germination of photoblastic lettuce seeds. Plant Physiol. 118:1517-1523.

van der Woude, W.J. and V.K. Toole. 1980. Studies of the mechanism of enhancement of phytochrome-dependent lettuce seed germination by prechilling. Plant Physiol. 66:220-224.

Vertucci, C.W., F.A. Vertucci, and A.C. Leopold. 1987. Water content and the conversion of phytochrome regulation of lettuce dormancy. Plant Physiol. 84:887-890.

Wien, H.C. 1997. Lettuce, p. 479-509. In: Wien, H.C. (ed.). The physiology of vegetable crops. CABI Publishing, Wallingford, UK.

Wurr, D.C.E. and J.R. Fellows. 1985. A determination of the seed vigour and field performance of crisp lettuce seedstocks. Seed Sci. Technol. 13:11-17.

Wurr, D.C.E., J.R. Fellows, D. Gray, and J.R.A. Steckel. 1986. The effects of seed production techniques on seed characteristics, seedling growth and crop performance of crisp lettuce. Ann. Appl. Biol. 108:135-144.

Yamaguchi, S., M.W. Smith, R.G.S. Brown, Y. Kamiya, and T. Sunday. 1998. Phytochrome regulation and differential expression of gibberellin $3 \beta$-hydroxylase genes in germinating Arabidopsis seeds. Plant Cell 10:21152126. 